\title{
Message Strategy Effects for Risk-Reduction Campaigns during Health Crises
}

\author{
Amir Heiman $^{1}$, Jacob Hornik ${ }^{2,3}$, Oded Lowengart ${ }^{4}$ \\ ${ }^{1}$ Department of Agricultural Management, Hebrew University, Rehovot, Israel; ${ }^{2}$ Peres Academic Center, Rehovot, Israel; ${ }^{3}$ School of \\ Management, Tel-Aviv University, Tel-Aviv, Israel; ${ }^{4}$ Guilford Glazer School of Business, Ben-Gurion University, Beer-Sheva, Israel. \\ Email: heiman@agri.huji.ac.il, hornik@pac.ac.il, odedl@bgu.ac.il
}

Received November $30^{\text {th }}, 2011$; revised January $6^{\text {th }}$, 2012; accepted January $17^{\text {th }}, 2012$

\begin{abstract}
Advertising campaigns carried out by firms post-health crises have been well documented in the literature, but the results, in terms of their effectiveness in recovering demand, are mixed. This paper examines the effect of risk-framed message appeal (aimed at reducing uncertainty about a product by elaborating upon new safety controls) on reductions in losses resulting from crises in comparison. The article develops a model that accounts for the effects of health crises and advertising with different information on sales. Using real market data, the study empirically shows that the choice of a risk-reduction advertising campaign has no significant on sales.
\end{abstract}

Keywords: Message Appeal; Message Framing; Crises Management; Market-Level Data

\section{Introduction}

Beef producers in Germany and the United States adopted two polar advertising strategies in their efforts to gain back consumers' patronage after the outbreak of bovine spongiform encephalopathy (BSE, or mad-cow disease) at the end of the twentieth century. The Bavarian cooperative of beef producers in Germany launched a television campaign based on a risk-reduction message that asserted the high standards of beef raised in Bavaria and implied that it was safe from BSE [1]. In contrast, the American Cattlemen's Beef Association directed its postBSE-crisis advertising toward the hedonic aspects of the product (e.g., taste). Advertisements that focus on the taste attribute of frequently purchased food items serve mainly as a reminder to consumers and should not offset any downward shift in negative perceptions. However, a focus on taste has been shown to offset the negative effect of information about health hazards [2]. Highlighting the benefits of the product and implying that consumers should consider the trade-off between increased risk and superior taste, variety, or other dominant attributes is not a common communications practice. In fact, many of the companies that faced health problems from the use of their have directed their communications recovery efforts toward health attributes. Communications strategies that focus on health attributes either aim to ensure buyers that safety measures have been taken to avoid future problems (e.g., Bavarian cattle producers cooperative; Mattel's second toy recall) or aim to explain the low likeli- hood of a consumer being affected (e.g., McDonald's response to an implied relationship between intestine illness and consumption of hamburgers).

Consumers' trust in safety measures and the adjustment of exaggerated risk perceptions are two different components of health risks [3]. The choice of adjusting perceptions, increasing trust in safety measures, or stressing the benefits of consumption, which translates to an increased willingness to accept risk, can have many possible outcomes that need to be taken into account when designing a post-crisis communications campaign [4,5]. Previous studies that explored communications strategies that aimed to recover demand after food crises have supported their arguments on anecdotal evidence (e.g. [6]) or experiments (e.g. [7]), rather than on real market data.

A different stream of literature that analyzes the effectiveness of post-health-crisis ads aimed to reduce perceived risk after a crisis is based on market data but does not account for the effect of the type of message (appeal) communicated (e.g., [8,9]) . Kinnucan, et al. [10] posits that the different outcomes of post-crisis generic advertising campaigns result from selection of the advertisement expenditure as the dependent variable without considering the campaigns' communications strategy. The purpose of this article is to provide insight into the research in this area by analyzing the effectiveness of an ad campaign during a health crisis with a message aimed to reduce concerns about the risks of health hazards. The analysis is based on real market data taken from the Fish 
Growers Association (FGA), which represents $70 \%$ of the fish industry's production in Israel. During a health crisis, the association chose an advertising strategy to reduce uncertainty about health hazards associated with consuming fish. The FGA campaign features two slogans: "Fish are back on the plate," and "Fish with the quality control mark [of FGA] are safe." A strategy that reminds consumers about a scare may prove a double-edged sword, as it can make information on health and uncertainty more accessible and suppress the benefits associated with consumption of a product. This study aims to analyze the effectiveness of the message strategy (i.e., risk reduction) on sales during a crisis.

\section{Theoretical Overview}

The literature on the effect of negative information conveyed in food-recall incidents coupled with the literature of advertising in general on demand has produced some contradictory conclusions. Swartz and Strand [9], for example, studied the effect of negative media coverage on health hazards from consumption of oysters in Baltimore and found that positive advertising reduced the losses from the unfavorable information. Smith, et al. [8], in contrast, studied the effect of a milk recall in Hawaii and found that advertising did not offset the negative effect of bad publicity, even when a third party (i.e., a government official) stated that the product was safe. Smith et al. [8] concluded that consumers discounted the positive messages. They note, however, that because the incident they studied extended 15 months, the decline in demand could have stemmed from changes in consumer tastes.

Liu, Huang and Brown [11] use the prospective reference modeling approach in the same Hawaiian case to show that advertising reduced losses from unfavorable media coverage. Marsh, Schroeder and Mintert [12] examine the effect of meat recall on demand and found that media coverage had a negative effect but that the intensity of the coverage, measured as the number of articles in the press, had no significant impact on demand. Kinnucan et al. [10] examine the impact of negative advertising information on the possible effects of eating beef on heart disease. Their results indicate that the contemporaneous effects of health information are greater than the lagged effects, which indicates that the effect of information depletes rapidly and that advertising has a minor effect on demand. Verbeke and Ward [13] reported similar results.

The conflicting findings and marginal effects of advertising may be related to the quantification of the advertising variable in monetary value rather than the specification of dummy variables for ad content (e.g., the type of message appeal [10]). Using health communications terminology $[14,15]$, we compare the two major strate- gies of risk- and gain-framed ads. Consumers receiving exposure to gain-framed messages have stronger intentions to comply than do consumers who face risk-framed messages.

The theoretical explanation is based on self-efficacy theory $[5,14,16]$. Consumers' intention to behave is a function of greater regulatory fit of the message to enhance self-efficacy in a gain-framed promotion format than in a risk reduction risk-framed message. In other words, in health communications contexts, communications designed to enhance outcome expectations or beliefs about a product's effectiveness may enhance response efficacy and demand more than advertisements designed to frame the message only around reducing risks.

This article considers cases in which an advertising message aimed to reduce uncertainty by elaborating on new safety control measures (using a quality-control label) that the fish industry had adopted after two health crises. The study compares the effect of the post-crisis ad campaigns on sales in times of crises to the effect of ads aimed to increase sales in times of no crisis.

\section{Modeling the Effect of Information on Demand}

Consumers maximize their utility from a vector $J$ of food commodities, $J=1 \cdots N$. The consumption of one unit of commodity $j$ supplies consumers with the quantity of $x_{i j}$ of attribute $i$. The perception of $x_{i j}$ is information dependent. Consumers choose the quantity $Q_{i}$ that maximizes their utility under budget constraints and the set of price vector $P_{j}$. A linear approximation of the multiattribute Marshalian demand function for product $j$ prior to new information (e.g., [17] is given by

$$
D\left(Q_{j}\right)=a+\sum_{j=1}^{N} \sum_{i=1}^{M} w_{i} x_{i j}+\sum_{j=1}^{N} b_{j} P_{j}
$$

where $a$ is a constant representing product-specific preferences, $w_{i}$ is the importance weight of attribute $i$, and $x_{i j}$ is the quantity of attribute $i$ in product $j$ (perception).

Health crises require that ad campaigns convey information about health hazards, and they negatively affect the perception of product quality, which reduces the marginal utility of the product (e.g., [18]) and shifts the demand curve downward $[9,12]$. The change in the perception of quality that results from information on the performance of one or more attributes is known as a taste shifter [19].

Let $I_{t=1}^{t}$ denote the information about health hazards conveyed in a food crisis during period $t=1$. Consumers integrate their prior beliefs at time $t=0$ about the properties of the health attribute, $f_{0}$, with the new information received at period $t, I_{t}^{I^{-}}$. Some studies assume that consumers update the probabilities of adverse affect by 
negative information in a Bayesian manner [20]. Just [21] proposes flexible information (beliefs) updating that allows consumers to discount or increase the weight they give to the new information. Let $w_{P}$ be the weight given to the prior information and $w_{N}$ the weight given to the new information. The integrated perception of the health production is given by

$$
f_{1}=f_{0}^{w_{P}}\left(I_{1}^{-}\right)^{w_{N}}<f_{0}
$$

Assigning the updated properties of the production function to consumers' maximization problem yields lower demand for the affected product, and thus $D_{t=0}>D_{t=1}$, similar to Smith et al. [8], Mazzocchi [18], and Marsh et al. [12].

Empirical studies have captured the effect of negative information by incorporating a constant term (dummy) or trend variables $[8,12]$. Specifically, the econometric estimation of the demand with information is given by

$$
D\left(Q_{j}\right)=a+\sum_{j=1}^{N} \delta_{j}+\sum_{j=1}^{N} \sum_{i=1}^{M} w_{i} x_{i j}+\sum_{j=1}^{N} b_{j} P_{j}
$$

where $\delta_{j}$ is a constant measure that captures the effect of negative information (i.e., about health hazards) on demand. Given a constant budget constraint for a category (constant expenditure), the sum of constant shifters in the demand equations equals zero (i.e., $\sum_{j=1}^{N} \delta_{j}=0$ ); that is, decline in demand for one good is compensated by an increase in the demand for its substitutes.

If information about health hazards reduces consumers' perception of product quality, then information about products' benefits changes the perception of product quality with respect to specific attributes and may offset the potential decline in demand. Generic advertisements are modeled as a separate shifter variable of the demand, as is that of unfavorable information [10]. Let $\gamma_{j, t}$ and $\psi_{j, t}$ denote risk-framed and gain-framed ad campaigns held at time $t$ and focusing on product $j$, respectively. The econometric estimation of the demand after exposure to negative information at time $t-1$ and advertisement at time $t$ is given by

$$
\begin{aligned}
D\left(Q_{j, t}\right) & =a+\sum_{j=1}^{N} \delta_{j, t-1}+\sum_{j=1}^{N} \gamma_{j, t} \\
& +\sum_{j=1}^{N} \psi_{j, t}+\sum_{j=1}^{N} \sum_{i=1}^{M} w_{i} x_{i j, t}+\sum_{j=1}^{N} b_{j} P_{j, t}
\end{aligned}
$$

Outside of times of crisis, in general, gain-framed ads for fresh meat had only a marginal effect on sales [22]. In general, ads had a lesser effect than did negative information $[10,11]$, that is, bad news is more powerful than good news. Therefore, we hypothesize the following:

$\mathbf{H}_{\mathbf{1}}:\left|\delta_{j, t-1}\right|>\left|\gamma_{j, t}\right|$.
Kinnucan [10] postulates that adding dependent variables that enable the discrimination of ad campaigns according to their appeal, in addition to expenditures, improves estimation of the effectiveness of post-crisis ad campaign.

Health crises increase the perception of risk; thus, communications efforts during and after a health crisis should aim either to reduce consumers' perceived probability of becoming ill by providing information about the source of risk and probabilities [3] or to increase consumers' trust in the producer, thereby reducing risk [19]. A third venue is to advertise taste, convenience, or higher-level attributes such as brand or nostalgia (e.g., [8]).

The choice between a campaign based on a riskframed (reduction) message and one based on gain-framed (e.g., sensual) product advantages needs to take into account that advertising focused on risk reduction may prime a health attribute. Priming on a certain attribute increases the likelihood that the attribute will be more accessible to consumers, and therefore retrieved more easily from memory in subsequent judgment or choice tasks. Consequently, consumers will use that attribute more heavily in judgment tasks [23]. Thus, a campaign based on risk reduction increases the likelihood that risk consideration will dominate consumers' subsequent choice tasks.

$\mathbf{H}_{2}: \gamma_{j, t} \leq 0$, where $\gamma_{j, t}^{A^{r}}$ is the effect of loss-framed advertisement priming on risk reduction.

The impact of negative information diminishes over time; as a result, demand increases over time, not necessarily to its initial level but to a higher level than in the midst of the crisis $[8,18]$. Natural recovery (i.e., the effect of time on sales; [8]) is enhanced by consumers' resistance to changes in their eating habits rather than in the food on their plate, which drives them to be more cautious in how they handle and cook meat [24].

Tybout et al. [7] shows in a lab experiment that denying formerly unfavorable information increases consumers' unfavorable judgment of a product. Braun-LaTour et al. [6] reaches a similar conclusion in a case study analysis, suggesting that it is more effective to emphasize the firm's nostalgic values. Messer et al. [2] shows in a lab experiment that a campaign focusing on the taste attribute ("Beef, it's what's for dinner") offset devaluation of beef from information about BSE. In contrast to experimental studies that advocated use of the gain-framed message as a recommended dose after health crises, studies based on real market data found that gain-framed messages are not statistically different from zero in many cases (e.g., [10]) or have small demand elasticity [12]. Thus,

$$
\mathbf{H}_{3}: \psi_{j, t} \rightarrow 0 \text {. }
$$


While the findings of Tybout et al. [7] and Messer et al. [2] are based on controlled experiments, the crises literature based on real market events has not included message appeal (priming element) in its analyses [10].

This article departs from previous studies to analyze a real market crisis with specific, risk-reduction message content. Because the message is based on real-life crises, we could not conduct a controlled experiment. As a result, some confounding effects of different variables may occur. For example, modeling advertising and crises effects may lead to identification problems, thus making it difficult to isolate the effect of each event on demand or revenues. To address this issue, this investigation uses a hierarchical modeling approach that allows for different events to contribute to the total explained variance of the model. In other words, even if there were a potential identification problem, analyzing the additional variance explained by one of the variables may alleviate some of the confounding effect.

\section{Empirical Study}

This empirical study aims to identify the effect of message content on consumers' purchasing behavior. To this end, the study included gathering market data over five years on aquacultured (freshwater-farmed) fish sales and used a hierarchical linear sales function to estimate the effect of ad message content on sales to resolve potential variable identification problems (for a more detailed explanation, see the subsequent analyses).

\subsection{Method}

Researchers studying the contribution of advertising to demand during and after health crises estimate either demand assuming constant supply, or both supply and demand simultaneously. The latter is motivated by the argument that at every period we observe equilibrium (intersection of demand and supply); while one expects the demand curve to shift downward in response to negative information about health hazards, one needs to take into account shifts in the supply curve that occur both as an adjustment to the decline in demand and as a response to exogenous changes in input costs. This simultaneous estimation method is long-run estimation. The other method, short-run estimation, estimates the effect of advertising on sales (revenue), assuming that the supply in the relevant time period is constant. Constant supply is relevant in the case of marketing orders, or in our case, where the crises and advertisement are limited to very short time periods (i.e., the first crisis ended lasted one month, and the second crisis lasted four months).

The nature of production in aquaculture is such that production decisions are made before demand and input costs are realized. Once production choices are made, it is not possible to change them; thus, the supply side is held constant. The only flexibility producers have in such an industry involves inventory decisions, which are limited in nature. Aquaculturists can keep fish in the growing pools for additional periods (beyond the optimal growing period, but they incur suboptimal production costs and may have problems selling the larger product) or freeze the fish and sell them in the future. Thus, supply may shift to the right with lagged inventory, and so we added inventory as an explanatory variable in the empirical analysis. This paper uses the short-run method in this study for two main reasons: it is more consistent with the biological nature of aquaculture production, and it is more realistic in terms of the short duration of crises.

The short-run effect on sales is greater than the longrun effect, ranging from a $\$ 5$ to a $\$ 20$ increase in sales per \$1 spent on advertising in the short run, compared to a $\$ 2$ increase in sales in the long run (e.g., [25,26]). Because this research uses short-run estimation, in which the contribution of advertising to sales represents an overestimation of advertising's long-run contribution, if results reveal a negative contribution as stated in $\mathrm{H}_{2}$, then use of the simultaneous approach will produce more conservative results.

\subsection{Data}

The two crises examined in this study occurred over six months. In February 2003, the E. coli crisis began when a television report revealed that fishing operations were fishing in the Mediterranean Sea near the pipeline outlets for the Tel Aviv metropolitan area's sewage recycling site. The Ministry of Health decided to recall all fish in the marketplace, including aquacultured fish, which had not been affected. The official recall took seven days, and only afterward did the ministry announce that aquacultured fish were safe and could be safely consumed [27]. By some estimates, sales of aquacultured fish dropped in the first two weeks after the recall by $70 \%$ [27] our estimates are lower, possibly attributable to the motivations and accuracy of statements made to the press), causing damages of about $\$ 3.5$ million. On November 11, 2003, a television report revealed that a freshwater fishery in Israel's northern valley was using the water disinfectant Malchit Green, which the Ministry of Health had banned as a known potential carcinogen [28]. The report spawned a wave of unfavorable publicity in the press, and the ministry ordered a fish recall and banned sales of all freshwater fish for two weeks [29].

In both cases, the FGA, which represents more than $70 \%$ of fish growers in the country, took immediate action by establishing a crisis team that launched ad campaigns after the recalls had ended. In the sewage case, the message aimed to reduce risk by differentiating between aquacultured fish and fish from the sea. Aquacultured 
fish came with a sticker (on packaged fish) or was indicated by in-store banners with the logo of certified fish. The campaign was broadcast by local and national radio programs, as well as during television entertainment and news programs, with the slogan "It is safe to eat certified fish” (http://www.laniado.co.il/_Articles/Article.asp?CategoryID=134\&ArticleID=138). This kind of advertisement is a loss-framed message that aims to adjust the perception of risk by providing information about the likelyhood of exposure to health hazards caused by consumption.

After the Malchit Green crisis, the ad message again aimed to reduce risk perception: a celebrity was hired to announce that fish were safe and "back on the plate (menu)." National and local radio stations broadcast the campaign for one and two weeks, respectively, and it ran in national and local newspapers, was advertised on buses, and was mentioned 33 times during television shows. The Malchit Green ad is a loss-framed message aimed to reduce risk perception by increasing consumers' trust in the product's quality-control process.

The data used in this study were obtained from two sources. First, we acquired sales quantities of aquacultured fish from the Israeli FGA (www.amd.co.il), which collects monthly sales data from aquaculturists and wholesalers. The total quantity of fish was computed by dividing the quantities supplied by the FGA by the share of production of that association. Retail fish prices were obtained from the agricultural division of the Israeli Central Bureau of Statistics (CBS, www.cbs.gov.il). This paper uses the same source to gather the price of chicken (i.e., substitute product) and the index of agricultural input. Data was collected over a period of 62 months between January 2000 and February 2005. The prices are indexed to the basic index of January 2002, using the price index published by CBS.

\subsection{Analysis}

The first step in the analysis determined the existence of seasonality effects in the data, as this study uses a timeseries-type data set. Figure 1 presents data on the monthly sales of fish over 60 months.

The data reveals two peaks in sales in each 12-month period, attributed to two major holidays for which fish is the traditional dish in many households, the eve of the Jewish New Year and Passover. The two crises occurred in weeks 38 - 39 (E. coli) and weeks 47 - 49 (Malchit Green) and appear at the bottom of the sales curve. In addition to the two crises that affected demand, very cold weather and freezing in winter 2004 caused fish mortality. This is a supply-side crisis; thus, we added it to test whether the dummy variables capture changes in revenues during all times of crisis. It could be that seasonality effects contributed to this. To account for seasonality effects, we used two variables, New Year's Eve (HOLIDAY-1) and Passover (HOLIDAY-2), in the empirical model of sales used in this study.

Some overlap during the time of crisis and the time of the ad campaign may cause an identification problem. Therefore, three more variables were added to designate the three crises, in order to identify the effect of each component (i.e., seasonality and crises). Dummy variables were used to represent the effects of the two crises (CRISIS-1 for the E. coli crisis, CRISIS-2 for the Malchit Green crisis, and CRISIS-3 for the freeze of 2004).Next, the study explored whether inventory plays a role in controlling the supply side of the market, as noted earlier. Figure 2 presents the average quarterly inventory of fish over 62 months.

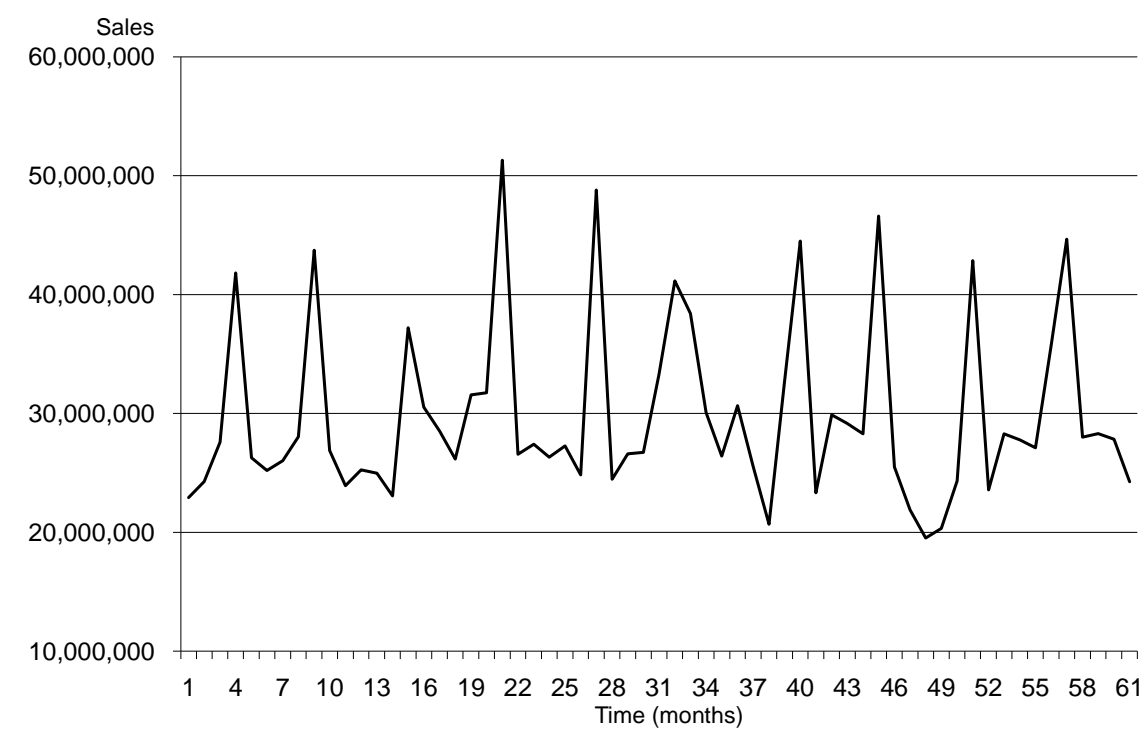

Figure 1. Fish sales (monetary) over a 62-month period. 


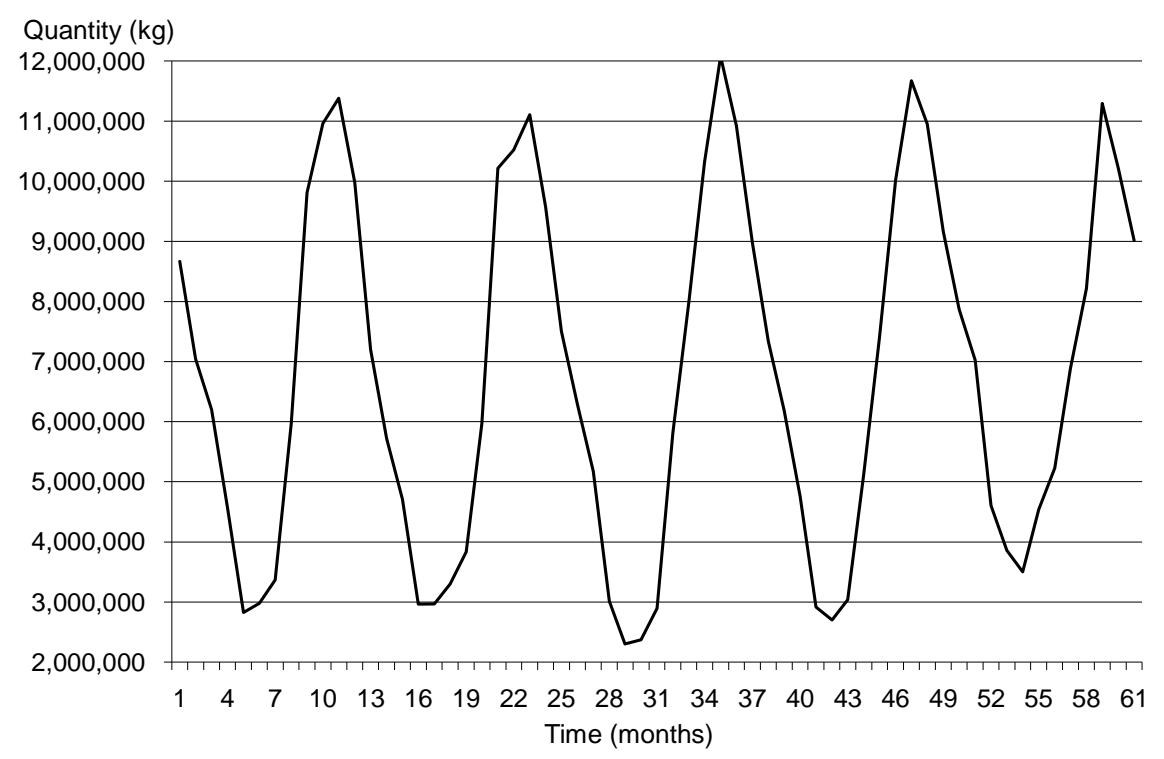

Figure 2. Fish inventory (quantity) over a 62-month period.

Because of the changes in inventory over time, this study uses this variable in the empirical model as a dependent measure together with quantity (sales). To estimate whether or not the crises results in a price reduction that compensated for the potential loss in sales, the study compares prices at the time of the crises with the prices before and after the crises (with comparable time frames). Figure 3 presents the price level over 62 months.

The data analysis shows no significant differences in the price levels within the three time frames of both crises (0.359 for Malchit Green, weeks 4 - 49; 0.292 for $E$. coli, weeks 38 - 39). The results indicate that the FGA did not use price reduction as a way to keep sales from falling. Another variable that might affect demand, and therefore sales, is the price of substitutes products. Because negative information about health hazards of eating freshwater fish has a minor influence on frozen fish sales and because chicken was not found to be a substitute for fish, the study includes the price of frozen fish as a measure of the substitutability of freshwater fish (i.e., FROZEN-FISH-PRICE).

This paper uses ad appeal (i.e., the message conveyed) as an explanatory variable in the model. However, simple use of this variable can create additional identification and multicollinearity problems, as advertising about the safety of eating fish was carried out primarily during the two crises. In the two crises, the campaign started after recall and lasted longer than the crises themselves. Still, there is a need to account for such possibilities; thus, an attempt was made to resolve this problem by adopting a hierarchical estimation method. That is, it estimates the model with all explanatory variables, excluding advertising, and then estimates the full model (including advertising variables). Testing whether the additional $\mathrm{R}^{2}$ of the model is significant indicated that multicollinearity or identification problems were not critical in the estimation process. The first stage of the estimation procedure or the sales of fish (total market sales) is as follows:

$$
\begin{aligned}
\text { REVENUES }= & \beta_{0}+\beta_{1} \text { HOLIDAY }-1 \\
& +\beta_{2} \text { HOLIDAY }-2+\beta_{3} \text { CRISIS }-1 \\
& +\beta_{4} \text { CRISIS }-2+\beta_{5} \text { CRISIS }-3 \\
& +\beta_{6} \text { FROZEN }- \text { FISH } \\
& - \text { PRICE }+\beta_{7} \text { INVENTORY }
\end{aligned}
$$

where REVENUES is the monetary monthly sale amount, HOLIDAY-1 and HOLIDAY-2 are indicator variables representing New Year's and Passover, respectively. CRISIS-1, CRISIS-2, and CRISIS-3 are indicator variables representing the Malchit, E. coli, and 2004 freeze crises, respectively. FROZEN-FISH-PRICE denotes the price of frozen fish served as a substitute product for fresh fish, and INVENTORY is the quantity (kilograms) of inventtory fish representing possible updates of the supply by aquaculturists in light of changes in demand, input prices, and biological conditions.

In the second stage, the current research uses the same functional form for the sales estimation equation and added the advertising variable corresponding to the Malchit crisis as follows:

$$
\begin{aligned}
\text { REVENUES }= & \beta_{0}+\beta_{1} \text { HOLIDAY }-1 \\
& +\beta_{2} \text { HOLIDAY }-2+\beta_{3} \text { CRISIS }-1 \\
& +\beta_{4} \text { CRISIS }-2+\beta_{5} \text { CRISIS }-3 \\
& +\beta_{6} \text { FROZEN }- \text { FISH }- \text { PRICE } \\
& +\beta_{7} \text { INVENTORY }+\beta_{8} \text { ADV } \\
& - \text { MALCHIT }
\end{aligned}
$$




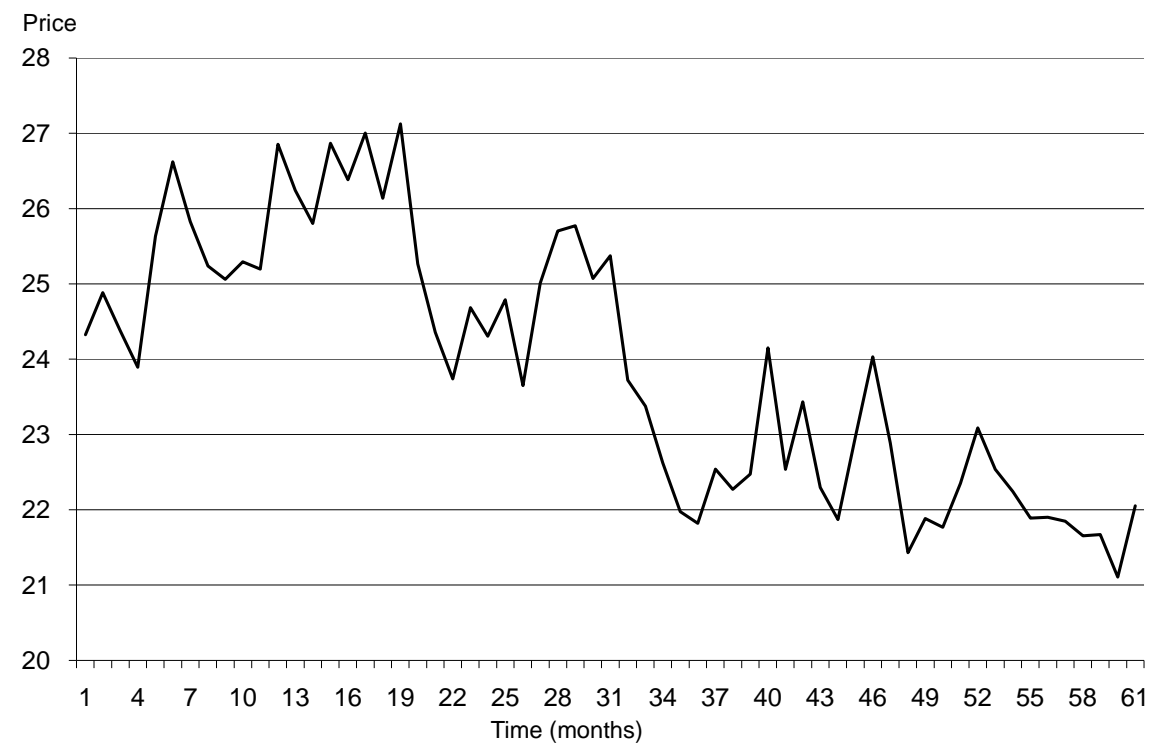

Figure 3. Fish price over a 62-month period.

where ADV-MALCHIT is advertising in time of the Malchit Green crisis with a 0 - 1 measure to represent content and not a monetary or volume-based value. In the third stage, the paper uses the functional form of stage 2 and added the advertising variable for the $E$. coli crisis as follows:

$$
\begin{aligned}
\text { REVENUES }= & \beta_{0}+\beta_{1} \text { HOLIDAY }-1 \\
& +\beta_{2} \text { HOLIDAY }-2+\beta_{3} \text { CRISIS }-1 \\
& +\beta_{4} \text { CRISIS }-2+\beta_{5} \text { CRISIS }-3 \\
& +\beta_{6} \text { FROZEN }- \text { FISH }- \text { PRICE } \\
& +\beta_{7} \text { INVENTORY }+\beta_{8} \text { ADV } \\
& - \text { MALCHIT }+\beta_{9} \mathrm{E}-\mathrm{COLI}
\end{aligned}
$$

where ADV-ECOLI is advertising during the E. coli crisis with a 0 - 1 measure as noted earlier. In the fourth stage, the paper uses the functional form of stage 3 and added the positive advertising variable as follows:

$$
\begin{aligned}
\text { REVENUES }= & \beta_{0}+\beta_{1} \text { HOLIDAY }-1 \\
& +\beta_{2} \text { HOLIDAY }-2+\beta_{3} \text { CRISIS }-1 \\
& +\beta_{4} \text { CRISIS }-2+\beta_{5} \text { CRISIS }-3 \\
& +\beta_{6} \text { FROZEN }- \text { FISH }- \text { PRICE } \\
& +\beta_{7} \text { INVENTORY }+\beta_{8} \mathrm{ADV} \\
& - \text { MALCHIT }+\beta_{9} \mathrm{ADV}-\mathrm{ECOLI} \\
& +\beta_{10} \mathrm{ADV}-\mathrm{GAIN}
\end{aligned}
$$

where ADV-GAIN is gain-framed advertising (when used) with a 0 - 1 measure, as noted earlier.

\section{Results}

This study examines the effect of the strategy of adver- tising messages on sales in times of crisis. Identifying the effect of the advertising variable combined with other relevant variables might explain fish sales in both regular sales periods and during times of crisis. This section starts with the results from the first stage. Table 1 presents the results of the linear model for the effect of crises on revenues.

The goodness-of-fit measure, $\mathrm{R}^{2}$, of $72.24 \%$ provides face validity to the relevance of our choice of explanatory variables and the effect of crises on revenues. The second stage of the hierarchical regression resulted in an $\mathrm{R}^{2}$ of $72.71 \%$, and the additional explained variance was not significant when compared with the previous stage. The third stage resulted in $\mathrm{R}^{2}$ of $75 \%$. Though the addition to the variance explained may not seem high, this addition is significant at the 0.043 level, thus indicating that the advertising campaigns explained changes in revenues and that the effect of advertising is beyond that of the crises effects. The fourth stage resulted in $\mathrm{R}^{2}$ of $74.79 \%$, and the additional explained variance was not significant compared with the previous stage.

Several general conclusions can be drawn from this analysis about the effect of the explanatory variables on fish sales. The first is that there is a differential negative effect of crises on the sales of this product. That is, the Malchit Green crisis had a significant effect on sales, while the other two events, the E. coli crisis and 2004 freeze did not have such an effect.

Moreover, there is a real effect of substitution, as the price of frozen fish was significant. That is, consumers used frozen fish as a substitute for fresh fish. This substitution poses a challenge to marketers and aquacultureists, because the import of frozen fish becomes a relevant threat. Seasonality effects are important in this market as 
Table 1. Hierarchical regression results.

\begin{tabular}{|c|c|c|}
\hline Variable & Coefficients & Significance level \\
\hline \multicolumn{3}{|l|}{ Stage 1} \\
\hline Constant & 18382216.3 & 0.0050 \\
\hline Holiday-1 & 17097648.1 & 0.001 \\
\hline Holiday-2 & 13839633.6 & 0.001 \\
\hline Crisis-1 & -7742727.9 & 0.005 \\
\hline Crisis-2 & -1836894.5 & 0.547 \\
\hline Crisis-3 & -2304647.2 & 0.461 \\
\hline Frozen fish price index & 101696.5 & 0.116 \\
\hline Inventory & -0.065 & 0.743 \\
\hline \multicolumn{3}{|l|}{ Stage 2} \\
\hline Constant & 17983115.9 & 0.006 \\
\hline Holiday-1 & 17006572.1 & 0.001 \\
\hline Holiday-2 & 13771010.1 & 0.001 \\
\hline Crisis-1 & -5712254.4 & 0.094 \\
\hline Crisis-2 & -1945734.6 & 0.524 \\
\hline Crisis-3 & -2426333.7 & 0.438 \\
\hline Frozen fish price index & 106369.2 & 0.102 \\
\hline Inventory & -0.061 & 0.757 \\
\hline Advertising malchit & -3235746.1 & 0.322 \\
\hline \multicolumn{3}{|l|}{$\underline{\text { Stage } 3}$} \\
\hline Constant & 18003647.8 & 0.005 \\
\hline Holiday-1 & 16977779.5 & 0.001 \\
\hline Holiday-2 & 13794235.9 & 0.001 \\
\hline Crisis-1 & -5766690.9 & 0.082 \\
\hline Crisis-2 & 3946674.7 & 0.339 \\
\hline Crisis-3 & -2465751.5 & 0.417 \\
\hline Frozen fish price index & 105137.7 & 0.096 \\
\hline Inventory & -0.046 & 0.811 \\
\hline Advertising malchit & -3235061.9 & 0.307 \\
\hline Advertising E. coli & -11777867.8 & 0.043 \\
\hline \multicolumn{3}{|l|}{$\underline{\text { Stage } 4}$} \\
\hline Constant & 17968073.4 & 0.006 \\
\hline Holiday-1 & 16972187.3 & 0.001 \\
\hline Holiday-2 & 13782531.7 & 0.001 \\
\hline Crisis-1 & -5767009.9 & 0.346 \\
\hline Crisis-2 & 3933059.6 & 0.085 \\
\hline Crisis-3 & -2472348.8 & 0.421 \\
\hline Frozen fish price index & 105733.1 & 0.099 \\
\hline Inventory & -0.048 & 0.806 \\
\hline Advertising malchit & -3241746.2 & 0.311 \\
\hline Advertising E. coli & -11774893.3 & 0.045 \\
\hline Generic advertising & -371031.1 & 0.929 \\
\hline
\end{tabular}

well, as all seasonality variables (holidays) had significant effects on sales.

The paper focuses on the effect of loss-reduction messages compared to the effect of gain-framed messages. Loss-reduction messages may make information about health attributes more accessible and thus may cause damage rather than increase demand. The non-significant effect of advertising during the Malchit Green crisis and the significant, negative effect of ad content during the $E$. coli crisis partially support $\mathrm{H}_{2}$ and fully support $\mathrm{H}_{1}$. The negative coefficient indicates that the advertising campaign caused aqua-culturists to lose about NIS 11.8 million (US\$2.8 million). As advertising occurred mostly at the time of the two crises, our study had a market-level, experiment-type design that allowed us to isolate the effect of advertising in times of crisis on demand from that at other times and to gain a better understanding of the role of advertising at such times. The results indicate that risk-reduction campaigns are not the proper way to offset losses.

Choice of a message that aims to reduce risk is important, as the combination of message and the type of crisis may be fatal. While our finding that gain-framed advertising does not have a statistical significant affect on demand agrees with findings of previous studies, we did find that loss-framed messages can accelerate the reduction of demand.

In summary, for the first event (e.g., Malchit Green), the crisis coefficient is significant but the advertising coefficient is not significant. For the second event (e.g., $E$. coli), the crisis coefficient is not significant while the advertising coefficient is significant but negative. On the basis of these results, there is support for $\mathrm{H}_{1}$; bad news (i.e., crisis) is more powerful than good news (i.e., safety advertising). Results also find support for $\mathrm{H}_{2}$ : a riskreduction message increases the likelihood that consumers more heavily weight risk consideration in the judgment task, which may cause an adverse effect. On the basis of these results, an ad campaign that focuses on health aspects (loss-framed message) is less likely to recover sales.

\section{Discussion and Conclusions}

The biological nature of food means that health crises are unavoidable in the food industry, regardless of qualitycontrol efforts. Better quality control can reduce the probability of such events, and firms should pursue advanced methods to improve quality and avoid such breakdowns and problems. However, the reality is that guaranteed $100 \%$ quality is unlikely. The realization that sooner or later marketers in such industries will handle health crises has led large food manufacturers and fast-food chains to construct crisis teams to prepare alternative strategies for use should such an event occur. However, having a 
crisis team did not prevent the FGA from falling into the trap that larger and more experienced companies have succumbed to: choosing the wrong advertising message. Coca-Cola and Pepsi made a similar mistake when they questioned the accuracy of an Indian lab's results and suffered a decline in profits [30]. Tybout et al.'s [7] and Braun-LaTour et al.'s [6] studies suggest that at the stage of rebuilding brand values in times of crisis, it is better not to discuss health-risk factors, directly or indirectly, and that ad campaigns that focus on gain-framed, uppervalue attributes, such as fun, enjoyment, and taste, are more likely to offset the loss caused by health problems or at least are less likely to slow sales losses.

Pennings et al. [3] analyze the effect of BSE in consumers' purchase decisions and found that information about health hazards affects choice by changing either risk perceptions (judgment about the individual probability of infection) or risk attitude (similar to risk aversion). The recovery strategy, therefore, depends on whether the risk perception or attitude is affected. If consumers' perceptions are changed, providing new information about the accurate probabilities of infection is beneficial. Conversely, if risk attitude is affected, then it is more efficient to increase consumers' willingness to accept risk through strategies such as highlighting a product's taste attributes [2]. Tybout et al.'s [7] and Braun-LaTour et al.'s [6] two studies highlight the complexity of handling the health dimension in times of crises, by either avoiding this dimension altogether or by using a differential treatment based on the type of effect consumers experienced (i.e., health dimension) as a result of a crisis.

This study examines actual consumption data, which increases the validity of the findings. The study differs from those of Kinnucan et al. [10] and Marsh et al. [12] in that we analyze the context of the advertisement rather than the expenditure. The FGA ad, aimed to offset the damage caused by health crises, did not have a significant effect on sales, and, in hindsight, was counterproductive. These findings provide market-based support for the theoretical argument that a message that highlights a product's health aspects when consumer memory of a crisis is still fresh might increase attention paid to health attributes, thereby increasing accessibility to information on health problems and negating the ad's potential productivity $[15,19]$.

From a managerial point of view, it would be wise to save resources and advertise taste or other non-health attributes after waves of a crisis have subsided. Many managers feel that they must react to unfavorable information disseminated about a product; however, our findings indicate an alternative strategic option: do nothing. As hard as it is for managers to not respond, such a strategy might save valuable resources (e.g. [5]).

The current study observation of the health crises leads to suggest the following ad strategies: do not advertise at the time of the crisis; advertise only after consumers' memories of the incident fade. During the crises, use public relations and direct communications with consumers about the measures that have been taken to fix the failure. After natural recovery has taken place, advertising that highlights the benefits (hedonic) of the product attributes, such as taste, needs to be implemented, as it may accelerate the recovery and build long-run demand. On the basis of theory and findings, managers should minimize as much as possible risk-framed messages that might relate with a product's health risks.

\section{REFERENCES}

[1] S. R. Herrmann and S. Krischik-Bautz, "Bovine Spongiform Encephalopathy and Generic Promotion of Beef: An Analysis for Quality from Bavaria,” Agribusiness, Vol. 18, No. 3, 2002, pp. 369-385. doi:10.1002/agr.10022

[2] K. D. Messer, H. Kaiser, C. Payne and B. Wansink, "Advertising Could Calm Food Safety Fears,” 2006.

http://www.foodnavigator-usa.com/news/printNewsBis.as p?id=69841

[3] J. M. Pennings, B. Wansink and M. T. G. Meulenberg, "A Note on Modeling Consumer Reactions to a Crisis: The Case of the Mad Cow Disease," International Journal of Research in Marketing, Vol. 19, No. 2, 2002, pp. 91100. doi:10.1016/S0167-8116(02)00050-2

[4] M. Dutta, "Health Information Processing from Television,” Health Communication, Vol. 21, No. 1, 2007, pp. 1-9. doi:10.1080/10410230701283256

[5] M. Rohem and A. Tybout, "Managing the Unthinkable: What to Do When Scandal Hits Your Brand,” In: B. Calder, Ed., Kellogg on Advertising \& Media, John Wiley, New York, 2008, pp. 159-177.

[6] K. Braun-LaTour, A. Michael, S. LaTour and E. F. Loftus, "Is That a Finger in My Chili? Using Affective Advertising for Postcrisis Brand Repair," Cornell Hotel and Restaurant Administration Quarterly, Vol. 47, No. 2, 2006, pp. 106-122. doi:10.1177/0010880405283623

[7] A. Tybout, B. J. Calder and B. Sternthal, "Using Information Processing Theory to Design Marketing Strategies," Journal of Marketing Research, Vol. 18, No. 1, 1981, pp. 73-79. doi:10.2307/3151315

[8] M. E. Smith, E. O. van Rosenswaay and S. R. Thompson, "Sales Loss Determination in Food Contamination Incidents: An Application to Milk Bans in Hawaii," American Journal of Agricultural Economics, Vol. 70, No. 3, 1988, pp. 513-520. doi:10.2307/1241489

[9] D. G. and I. E. Strand, "Avoidance Costs Associated with Imperfect Information: The Case of Kepone,” Land Economics, Vol. 57, No. 1, 1981, pp. 139-150.

[10] H. W. Kinnucan, H. Xiao, C. Hsia and J. D. Jackson, "Effects of Health Information and Generic Advertising on US Meat Demand,” American Journal of Agricultural Economics, Vol. 79, No. 1, 1997, pp. 13-24.

doi:10.2307/1243939 
[11] S. J. Liu, C. Huang and G. L. Brown, "Information and Risk Perception: A Dynamic Adjustment Process,” Risk Analysis, Vol. 18, No. 6, 1988, pp. 689-699. doi:10.1111/j.1539-6924.1998.tb01113.x

[12] T. L. Marsh, T. C. Schroeder and J. Mintert, "Impacts of Meat Product Recalls on Consumer Demand in The USA," Applied Economics, Vol. 36, No. 4, 2004, pp. 897-909. doi:10.1080/0003684042000233113

[13] W. Verbeke and R. W. Ward, “A Fresh Meat Almost Ideal Demand System Incorporating Negative TV Press and Advertising Impact," Agricultural Economics, Vol. 25, No. 3, 2001, pp. 359-374. doi:10.1111/j.1574-0862.2001.tb00215.x

[14] A. Keller, "Regulatory Focus on Efficacy of Health Messages," Journal of Consumer Research, Vol. 33, No. 3, 2006, pp. 109-114. doi:10.1086/504141

[15] M. Lee and S. Bicard, "Effective Message Design Targeting at Rebellious Risk-Taking Students," Health Communication, Vol. 20, No. 3, 2006, pp. 299-308. doi:10.1207/s15327027hc2003_9

[16] L. Block and P. Keller, "When to Accenturate the Negative: The Effect of Perceived Efficacy and Message Framing on Intentions to Perform a Health Related Behavior," Journal of Marketing Research, Vol. 32, No. 2, 1995, pp. 192-203. doi:10.2307/3152047

[17] J. Kim, G. M. Allenby and P. E. Rossi, "Modeling Consumer Demand for Variety,” Marketing Science, Vol. 21, No. 3, 2002, pp. 229-250. doi:10.1287/mksc.21.3.229.143

[18] M. Mazzocchi, "No News Is Good News: Stochastic Parameters versus Media Coverage Incidences on Demand Models after Food Scare," American Journal of Agricultural Economics, Vol. 88, No. 3, 2006, pp. 727-741. doi:10.1111/j.1467-8276.2006.00891.x

[19] A. Heiman and O. Lowengart, "The Effect of Information about Health Hazards on Demand in Frequently Purchased Commodities," International Journal of Research in Marketing, Vol. 25, No. 4, 2008, pp. 310-318. doi:10.1016/j.ijresmar.2008.07.002

[20] A. Bocker and C. H. Hanf, “Confidence Lost and Partially
Regained: Consumer Response to Food Scares,” Journal of Economic Behavior \& Organization, Vol. 43, No. 4, 2000, pp. 471-485. doi:10.1016/S0167-2681(00)00131-1

[21] D. R. Just, ”Information, Processing Capacity, and Judgment Bias in Risk Assessment," In: R. Just and R. Pope, Eds., A Comprehensive Assessment of the Role of Risk in US Agriculture, Kluwer Academic Publishers, Boston, Dordrecht, London, 2002, pp. 43-67.

[22] P. Ferrier and R. Lamb, "Government Regulation and Quality in the US Beef Market,” Food Policy, Vol. 32, No. 1, 2007, pp. 84-97. doi:10.1016/j.foodpol.2006.01.004

[23] A. Chakravarti and C. Janiszewski, "The Influence of Generic Advertising on Brand Preference," Journal of Consumer Research, Vol. 30, No. 4, 2004, pp. 487-502. doi:10.1086/380284

[24] R. Horowitz, "Putting Meat on the American Table: Taste, Technology, Transformation,” John Hopkins, Baltimore and London, 2006

[25] J. M. Crespi, "Generic Advertising and Product Differentiation Revisited,” Journal of Agricultural \& Food Industrial Organization, Vol. 5, No. 1, 2007, pp. 76-92. doi:10.2202/1542-0485.1153

[26] R. W. Ward and B. L. Dixon,, "Effectiveness of Fluid Milk Advertising since the Dairy and Tobacco Adjustment Act of 1983," American Journal of Agricultural Economics, Vol. 71, No. 3, 1989, pp. 730-739. doi: $10.2307 / 1242029$

[27] Kan-Naim (19.02.03), "Fish Growers Take Action to Recover Public Confidence." http://www.kan-naim.co.il/artical.asp?id=688

[28] V. Lubich, "The Ministry of Health Prohibits Consumption of Quacultured Fish and Raises Concerns in the Industry," Ynet, 2003. http://www.ynet.co.il/articles/0.7340.L-2823253.00.html.

[29] O. Yefet, "Supermarkets Are Removing Their Fish Products from Shelves,” 2003. http://www.ynet.co.il/articles/1.7340.L-2823422.00.html

[30] Global Information Network, "Reports of Contaminated Soda Dry Up Coke, Pepsi Sales,” 2006. 